* Mestre em Direito Negocial pela Universidade Estadual de Londrina (UEL). E-mail: baleotti@uel.br

** Doutor em Direito pela Pontifícia Universidade Católica de São Paulo (2004). Email: baleotti@uel.br

\section{Planos econômicos de estabilização nacional: uma análise sob o enfoque da responsabilidade extracontratual do estado e da segurança jurídica}

\author{
ECONOMIC PLANS OF NATIONAL STABILIZATION: \\ AN ANALYSIS SOB THE FOCUS OF LIABILITY THE \\ STATE AND SECURITY LEGAL
}

\author{
Edvania Fátima Fontes Godoy * \\ Marlene Kempfer **
}

Resumo: Um dos temas de relevância na atualidade refere-se à responsabilidade do Estado por dano decorrente de plano econômico. Tal questão envolve em seu núcleo aspectos jurídicos do direito privado e do direito público, evidenciando a indiscutível superação desta dicotomia. Partindo destas premissas, o objetivo da pesquisa é defender que em suas funções interventivas de planejamento o governo deve observar com cautela a política econômica a ser praticada, bem como suas modificações, sob pena de prejudicar o setor privado e a coletividade. Assim, o dano à ordem econômica deve ser uma preocupação jurídica. Nesse sentido, a finalidade da pesquisa é resgatar a história econômica dos planos de estabilização nacional (Plano Cruzado, Plano Bresser, Plano Verão, Plano Collor e Plano Real) e, a partir destas experiências, defender a responsabilidade extracontratual objetiva do Estado no caso de prejuízo, nos termos do art. $37, \S 6^{\circ}$ da $\mathrm{CF} / 88$, decorrente de planos econômicos nos quais os agentes envolvidos não têm liberdade de escolha entre alternativas viáveis para seus negócios. Entre os demais fundamentos desta responsabilização estão os argumentos da segurança jurídica, confiança e boa-fé, que devem reger as relações público-privadas. A pesquisa revela que a iniciativa privada, atuando no domínio econômico, necessita de um ambiente de estabilidade, previsibilidade, eficiência, porém, as experiências brasileiras mostram que em diversos planos econômicos esse ambiente não foi encontrado. A análise dos planos de estabilização adotados no Brasil no período de 19861994 demonstra que ocorreram intervenções imperativas que afetaram a livre iniciativa, a livre concorrência, o direito de propriedade, desconsiderando aspectos fundamentais de um Estado Democrático de Direito. Para alcançar os fins propostos utiliza-se o método científico-dedutivo com pesquisa na doutrina especializada. 
Palavras-chave: Planos econômicos. Juridicidade. Responsabilidade do

Abstract: One of the themes of relevance nowadays refers to State liability for damage arising from economic plans. This issue involves at its core legal aspects of private law and public law, demonstrating the undeniable overcome of this dichotomy. Starting from these premises, the goal of the research is to defend that in its interventional functions of planning the government should observe carefully the economic policy to be practiced, as well as its modifications, under the risk of impairing the private sector and the community. Thus, the damage to the economic order must be a legal concern. In this sense, the purpose of the research is to rescue the history of national economic stabilization plans (Cruzado Plan, Bresser Plan, Summer Plan, Collor Plan and Real Plan) and, from these experiments, to defend the State extracontractual and objective liability in case of loss, pursuant to the Article $37, \S 6$ of the Federal Constitution of 1988, arising from economic plans in which the agents involved do not have freedom of choice to viable alternatives for their businesses. Among the other grounds of this liability are the arguments of legal security, confidence and good faith, which comes to govern public-private relationships. The research reveals that the private sector, acting in the economic domain, requires an environment of stability, predictability, efficiency, however, the Brazilian experiences show that in several economic plans such and environment was not found. The analysis of the stabilization plans adopted in Brazil in the period of 1986-1994 shows that mandatory interventions occurred that affected the free initiative, the free competition, the property rights, disregarding fundamental aspects of a Democratic State of Law. To achieve the proposed aims it is used the scientific-deductive method with research in the specialized doctrine.

KEYWORDS: economic plans; juridicity; State responsability; legal security. 


\section{INTRODUÇÃO}

Entre os aspectos relevantes do Direito Econômico tem-se o âmbito da regulação sobre o domínio econômico, seus limites e a responsabilidade estatal por esta intervenção.

Somente a partir de 1980 começam a insurgir questionamentos nos Tribunais brasileiros em relação às políticas públicas econômicas adotadas pelos governos. É quando a inflação passa a atingir altíssimos índices e que medidas fortemente interventivas são adotadas, que se iniciam, mais intensamente, os questionamentos judiciais.

Diante de um panorama de instabilidades econômicas e também políticas os governos de José Sarney, Itamar Franco, Fernando Collor e o início de Fernando Henrique Cardoso optaram por uma intervenção normativa sobre as relações econômicas na tentativa de equilibrar o índice inflacionário nacional, entretanto, pode-se afirmar que em alguns casos as políticas econômicas aplicadas afrontaram direitos fundamentais na medida em que restringiram o direito de propriedade (confisco de dinheiro privado) e desrespeitaram o ato jurídico perfeito (contratos).

$\mathrm{O}$ intuito da pesquisa é analisar os aspectos econômicos e jurídicos que circundaram a política econômica adotada nos planos de estabilização nacional, Plano Cruzado (1986), Plano Bresser (1987), Plano Verão (1989), Plano Collor (1990) e Plano Real (1994), em face das repercussões que representaram para a atividade econômica e cidadãos.

A análise da intervenção do Estado nestes momentos permite classificá-las como imperativas e, assim, defender, a responsabilização do Estado pelos danos oriundos de políticas econômicas que acarretem prejuízos aos destinatários.

Os planos econômicos devem ter objetivos coincidentes com os fins do Estado de modo a legitimá-los. É direito constitucional que todas as medidas de governo efetivem as diretrizes constitucionais que compõem os objetivos e fundamentos da República Federativa (Art. $1^{\circ}$. Art. $3^{\circ}$ ) e a Ordem Constitucional Econômica (Art. 170). Se forem respeitadas, isto representa segurança jurídica, princípio fundamental para a economia que é regida pela racionalidade da eficiência, previsibilidade e planejamento. 


\section{PLANOS ECONÔMICOS DE ESTABILIZAÇÃO NO BRASIL}

Para entender os planos de estabilização econômica nacional e suas consequências é preciso resgatar os caminhos trilhados pela história econômica brasileira para aprender com os erros e planejar com coerência as vitórias futuras.

Os objetivos da política econômica confrontam-se com as dificuldades de integração da Estrutura com a Conjuntura, pois em muitos casos é difícil compatibilizar um Plano de Desenvolvimento, que engloba os aspectos estruturais, com um Programa de Estabilização, cujos aspectos são conjunturais. É na estrutura que residem os grandes problemas, as desigualdades regionais, condições da saúde, educação, altos níveis de concentração da propriedade, distribuição de riqueza e renda, baixo nível tecnológico, reduzida capacidade de poupança, desequilíbrios no balanço de pagamento, altas taxas de juros, entre outros fatores. Na conjuntura, o objetivo é de estabilização de preços, equilíbrio tributário, fiscal, monetário, cambial, somados a uma política de distribuição de rendas (BRITTO, 2004, p. 14-15).

Em sentido econômico a estabilidade remete a três objetivos básicos: manutenção do pleno emprego, estabilidade geral dos preços e equilíbrio da balança de pagamentos. Neste sentido o Brasil vivenciou cinco planos de estabilização econômica: Plano Cruzado (1986); Plano Bresser (1987), Plano Verão (1989); Plano Collor (1990), e Plano Real (1994).

Desde os anos 1980, os economistas procuravam entender o singularismo do processo inflacionário nacional, cujas tentativas de controle se iniciaram com o Plano Cruzado e não obtiveram êxito até a adoção do Plano Real, que se valeu da experiência dos planos anteriores, evitando equívocos como o congelamento de preços, o desrespeito ao direito contratual, o fator surpresa e a falta de cuidado na comunicação com a população. Na busca pela estabilidade monetária o Brasil enfrentou grandes erros, entre eles, a preponderância dos interesses das elites, a exclusão, a dominação do Estado por grupos e o enfraquecimento das instituições.

Fernando Herren Aguillar (2012, p. 81-185), em sua obra "Direito Econômico: do direito nacional ao direito supranacional", retrata inúmeros aspectos relevantes da história do Direito Econômico brasileiro, conforme adiante se pode verificar. A imposição de políticas públicas econômicas remonta aos tempos da colonização portuguesa. Tanto no período colonial, 
quanto no imperial e republicano, existiram parcerias público-privadas, concessões e permissões, monopólios, políticas monetária, agrícola, industrial e controle de preços. A história das políticas públicas econômicas se mistura com a própria história do Direito Econômico nacional.

O intento da pesquisa não é avaliar todas as políticas econômicas brasileiras, dado o grande número e a complexidade. O critério adotado foi o de buscar as políticas de estabilização nacional, a partir de 1986 até a adoção do plano Real, em 1994, a fim de analisar a possibilidade de responsabilização do Estado pelos danos causados aos particulares, tendo em vista um traço jurídico característico e relevante destes planos econômicos, a imperatividade.

Para que se possa fazer o recorte acima referido, é necessário compreender as transformações econômicas anteriores que lhe deram ensejo. A partir da década de 30 até o fim dos anos 80 do século passado o Brasil foi deixando de ser uma economia puramente agrária e rural e avançou no processo mundial de industrialização e urbanização. Pode-se dizer que esse processo ocorreu com a adoção de políticas econômicas de cunho nacionalista, objetivando a substituição de importações e a proteção da classe trabalhadora (AGUILLAR, 2012, p. 81-185).

O governo de Getúlio Vargas (1939-1945), cuja herança perdurou pelo menos 20 anos, deu ensejo às futuras intervenções estatais no domínio econômico. A regulação, nesse período, esteve centralizada no governo federal, em relação aos governos estaduais e municipais; no Poder Executivo, em relação ao Poder Legislativo; e no Estado em relação à iniciativa privada. Afora o breve primeiro período do governo Dutra, em que floresceu certo liberalismo econômico, o desempenho e a normatização dos serviços públicos estiveram predominantemente sob a responsabilidade do Estado (AGUILLAR, 2012, p. 81-185).

Em compensação às políticas econômicas de substituição de importações e proteção da classe trabalhadora, na década de 80 , o desequilíbrio nas contas governamentais somado a alta inflação e o crescimento da dívida externa limitaram e condicionaram as políticas públicas subsequentes. A partir das crises fiscais dos anos 1980 e seguintes, a incapacidade estatal de acompanhar as necessidades de investimento em infraestrutura e expansão de serviços públicos foi determinante para o ressurgimento de antigos dogmas clássicos de abstenção estatal. Verificase que desde então a iniciativa privada passa a conduzir o investimento em 
serviços públicos, sinalizando ao Estado a tarefa de regulá-los normativamente. Aos poucos o Estado vai deixando de ocupar o lugar de provedor de recursos para o desenvolvimento econômico (AGUILLAR, 2012, p. 81-185).

Nesse sentido, a ideia que tem dirigido às ações dos governos brasileiros é a de que a competitividade no setor público e no setor privado proporcionará ganhos quantitativos e qualitativos para o Estado e para os usuários dos serviços. Considerando essa realidade de ideais de diminuição do tamanho do Estado as questões propostas são: o que se pode exigir judicialmente do Estado, seja em relação à implementação ou a materialização de políticas públicas econômicas visando atingir as metas previstas na Constituição? O Estado deve ser responsabilizado pelos danos causados aos particulares em razão de seus planos econômicos?

\subsection{Plano Cruzado}

A Nova República iniciou-se em março de 1985 e entre os momentos econômicos mais instáveis vivenciados sem equívoco se destacam o do governo José Sarney (1985-1990) e o começo do governo Fernando Collor (1990-1992). Nos períodos em questão a inflação evoluiu para hiperinflação e no intento de enfrentá-la os governos impuseram ao país duras medidas econômicas visto que os esforços realizados no começo da década não haviam sido suficientes para que a inflação cedesse.

Ao longo do governo do Presidente José Sarney, que perdurou por cinco anos, foram lançados três planos de estabilização econômica: Plano Cruzado, em 1986; Plano Bresser, em 1987; e Plano Verão, em 1989. Embora esses planos tenham colaborado para que se verificassem momentos de crescimento, oriundos da expansão acumulada do produto, fracassaram no combate à inflação (CASTRO, 2005, p. 116).

A população foi informada sobre a adoção do Plano Cruzado no dia 28 de fevereiro de 1986, pela televisão. Os ministros João Sayad e Dílson Funaro, responsáveis por difundir a ideia, avisaram que não haveria mais inflação. Por ser o primeiro plano contra a inflação e dado o cansaço dos brasileiros em conviver com o aumento diário e intolerável dos preços, o governo obteve a anuência imediata e o compromisso dos cidadãos brasileiros. No enfoque econômico esse curto período da história ficou 
guardado na lembrança dos brasileiros como um tempo de experiências de estabilização da inflação malsucedidas.

É interessante situar o momento político que precede esse período econômico, marcado pelo movimento das "Diretas Já", que imbuído do sentimento de redemocratização gerava a falsa crença de que tudo se resolveria. Depois de 20 anos de regime militar, em 1984, o Brasil vivia um momento atípico de sua história. O movimento por eleições ganhava força aos poucos. A população brasileira, que se manifestava pelo direito de eleger o Presidente da República acreditava que a democracia além de trazer de volta as liberdades civis e políticas, traria o fỉm da inflação, a volta do crescimento e a tão desejada distribuição equitativa de renda.

$\mathrm{Na}$ concepção do economista Francisco Lopes, o enigma da estabilização poderia ser resolvido por meio de um pacto de adesão compulsória, ou seja, um congelamento de preços. Ao contrário, para Pérsio Arida e André Lara Resende, o congelamento implicaria em um endurecimento da economia, acabando com a autorregulação dos mercados via preços e, causando, ainda, várias distorções alocativas. A alternativa para a medida drástica de congelamento, batizada de "Proposta Larida", em tributo aos dois autores, propunha "desindexar a economia através da introdução de uma moeda indexada que circularia paralelamente à moeda oficial brasileira (na época, o Cruzeiro)" (CASTRO, 2005, p. 121).

Os planos de estabilização adotados por José Sarney (Cruzado, Bresser e Verão) seguiram a proposta de congelamento, enquanto o Plano Real (1994) seguiu a "Proposta Larida", porém, com algumas adaptações, pois a partir dos questionamentos sobre o fracasso dos planos de estabilização do período de 1985-1989 foi possível criar um plano de desindexação sólido como o Plano Real.

Dada a recuperação das contas externas do país a partir de 1983/ 1984, as reservas nacionais puderam alcançar um patamar elevado em 1985. Esse clima propiciou a adoção do Plano Cruzado no segundo ano de governo de José Sarney, pelo ministro da Fazenda Dílson Funaro, que substituiu Francisco Dornelles. O momento internacional também era favorável, com o preço do petróleo caindo e a desvalorização do dólar em relação às moedas europeias e ao iene (CASTRO, 2005, p. 124).

Medidas monetárias e fiscais foram incorporadas a partir de um "pacote fiscal" que tinha como fim acabar com as necessidades de financiamento no conceito operacional. Em 1986 extinguiu-se a chamada 
"conta-movimento". Com essa medida, os suprimentos automáticos que prejudicavam a atuação do Banco Central como gestor da política monetária foram abolidos. Porém, o gradualismo das medidas não gerou qualquer mudança sobre a inflação. Tendo em vista a constante elevação dos preços e o insucesso dos ajustes recessivos anteriores, o governo adotou a proposta do "Choque Heterodoxo" formulada por Francisco Lopes, denominado "Plano Cruzado", no dia 28 de fevereiro de 1986 (CASTRO, 2005, p. 124).

As medidas adotadas podem ser divididas, de modo analítico, em quatro grupos: a) reforma monetária e congelamento; b) desindexação da economia; c) índice de preços e cadernetas de poupança; e d) política salarial (CASTRO, 2005, p. 124-126).

Dadas às medidas adotadas, o sucesso inicial do Plano Cruzado foi rumoroso. $\mathrm{O}$ índice de preços ao consumidor baixou para praticamente zero e alguns jornais até chegaram a noticiar que o "dragão da inflação era de papel". As primeiras pesquisas de opinião apontavam índices quase unânimes de apoio ao governo de Sarney. Os "fiscais do Sarney" eram responsáveis pela denúncia de qualquer afronta aos preços tabelados. Não houve nesse começo, recessão, desemprego e arrocho salarial conforme previa a oposição. Apenas o setor bancário mostrou queda no índice de emprego (CASTRO, 2005, p. 124-126).

Alguns empresários, sob ameaça de greve, foram levados a conceder aumentos salariais além do abono, pois a expansão do emprego e o aumento do consumo traziam consigo o receio de interromper a produção. Esse aumento expressivo do consumo se deu sobre uma demanda já aquecida. Segundo Lavínia Barros de Castro (2005, p. 126), "ao contrário do que dizia a teoria inercialista, já havia uma pressão de demanda antes da adoção do Plano Cruzado".

Soma-se a esses fatores a redução das receitas de financiamento, associadas ao fim do imposto inflacionário e à queda real decorrente do congelamento de algumas tarifas públicas. De outro lado, as despesas do governo cresciam vultuosamente em razão do aumento dos gastos com a folha de salários do setor público.

A situação demonstrava que o governo tinha provocado uma expansão exagerada na oferta de moeda. A demanda superaquecida permitiu que começassem a surgir os sinais de desbastecimento da economia. Os produtos que haviam sido congelados com defasagem em relação ao percentual médio do período anterior desapareceram rapidamente das prateleiras. Começaram a aparecer dificuldades em relação ao preço de produtos da cesta básica, a 
diferença entre os preços de varejo e atacado tornou-se praticamente nula. Acompanhando a tendência, os preços do aço, combustíveis, tarifas públicas e outros produtos também apresentaram defasagens em relação aos custos. Vieram as filas e com frequência o fenômeno do ágio, que na prática, representava a volta da inflação (CASTRO, 2005, p. 127).

Em 24 de julho de 1986 foi anunciado o Cruzadinho, que consistia basicamente num pacote fiscal de medidas para desacelerar o consumo e financiar um plano de investimentos em infraestrutura e metas sociais. Os aumentos de preços decorrentes do pacote fiscal não foram incluídos no índice oficial de inflação na tentativa de impedir o acionamento do gatilho salarial. A medida gerou um descontentamento geral, pois era insuficiente para desaquecer o consumo e praticamente não gerou recursos para financiar o programa de investimentos anunciado pelo governo. Ou seja, além de não conter o consumo a expectativa de descongelamento deu um novo impulso à demanda (MODIANO, 1999, p. 54).

A insatisfação da população crescia a cada dia ante os problemas do ágio e do desabastecimento, que aumentou ainda mais com o expurgo do índice de preços oficial, levando o governo a recorrer às importações. Porém, a falta de costume brasileiro de importar acarretou muitos problemas, entre eles: congestionamento nos portos e demora na entrega dos produtos. Em outubro, o governo decretou uma desvalorização do cruzado de $1,8 \% \mathrm{e}$ proclamou uma política de minidesvalorizações eventuais, fundadas em um indicador da relação câmbio/salários. Porém, criou-se uma expectativa de desvalorização ainda maior, aumentando o ágio no mercado paralelo de dólar, antecipação de importações, adiamento de exportações, gerando uma deterioração ainda maior das contas externas (MODIANO, 1999, p. 54).

Uma semana após as eleições foi anunciado o Plano Cruzado II, gerando na sociedade a impressão de que as medidas restritivas estavam sendo adiadas por mero oportunismo político. A ideia do governo era basicamente aumentar os preços dos bens finais no intento de impedir repasses ao longo da cadeia produtiva. O Cruzado II tratava-se de um pacote fiscal com o fim de aumentar a arrecadação do governo por meio de alguns preços públicos (gasolina, energia elétrica, telefone e tarifas postais), e do aumento de impostos indiretos (automóveis, cigarros e bebidas). Impôs também que o aumento de preços dos automóveis, cigarros e bebidas deveriam ser expurgados do IPC ${ }^{1}$, objetivando adiar o $1^{\circ}$ disparo do gatilho

\footnotetext{
${ }^{1}$ IPC - Índice de Preços ao Consumidor.
} 
salarial. A reação da população apoiada por alguns novos governadores e congressistas obrigou o governo a desistir da proposta de expurgo. O governo simplesmente substituiu as ponderações do IPC, que se originaram do IPCA ${ }^{2}$, pelas ponderações do $\mathrm{INPC}^{3}$, que conferia menores pesos aos preços majorados pelo Cruzado II (MODIANO, 1999, p. 55).

O Cruzado II foi o meio encontrado para o abandono do congelamento, pois com as expectativas de retração da demanda para amortecer a aceleração inflacionária, o governo cedeu às pressões pela liberalização dos preços, suspendendo abruptamente quase todos os controles em fevereiro de 1987, quando foi declarado extinto o Plano Cruzado, com o fim do congelamento de preços e expressiva piora das contas externas, acarretando a decretação da moratória dos juros externos e prejudicando ainda mais a entrada de recursos externos no país.

Ao dissertar sobre o Plano Cruzado Eduardo Modiano (1999, p. 54), dividi o plano em três fases: i) março a junho de 1986, período que se caracteriza por uma queda substancial da inflação e também pelos primeiros indícios da existência de excesso de demanda na economia; ii) julho a outubro de 1986, identificado pelo total engessamento do governo diante do agravamento da escassez de produtos e à deterioração das contas externas; e iii) novembro de 1986 a junho de 1987, fracasso do Plano Cruzado com o retorno das altas taxas de inflação.

É possível avaliar que o Plano Cruzado foi um choque heterodoxo que tentou eliminar a indexação da economia trazendo mudança no padrão da sociedade a partir da busca de ativos reais, ações e consumo em detrimento de ativos financeiros, principalmente da poupança. $O$ congelamento de preços foi sem dúvida a medida que mais se destacou, pois agravou a estrutura de preços relativos da economia e comprometeu os setores com preços defasados, portanto, adota-se o congelamento de preços como parâmetro para análise das decisões judiciais referentes ao Plano Cruzado.

\subsection{Plano Bresser}

A O Plano econômico Bresser foi posto em prática no dia 12 de julho de 1987, reestabelecendo a prática do congelamento. O então Ministro da

\footnotetext{
${ }^{2}$ IPCA - Índice Nacional de Preços ao Consumidor Amplo.

${ }^{3}$ INPC - Índice Nacional de Preços ao Consumidor.
} 
Fazenda Luiz Carlos Bresser Pereira declarou que na luta contra a inflação seu plano entraria para a história do Brasil. Para tanto, foi criada uma nova base de indexação salarial - Unidade de Referência de Preços (URP) ${ }^{4}$.

Segundo Eduardo Modiano (1999, p. 55), tais medidas foram apresentadas à população como um programa de estabilização híbrido, com conteúdos ortodoxos ${ }^{5}$ e heterodoxos ${ }^{6}$ para combate à inflação. Todavia, o novo plano não possuía o objetivo de inflação zero, nem tampouco buscava acabar com a indexação da economia. $\mathrm{O}$ intuito era exclusivamente o de "promover um choque deflacionário com a supressão da escala móvel salarial e sustentar as taxas de inflação mais baixas com redução do déficit público".

$\mathrm{Na}$ vertente ortodoxa, contrariamente ao adotado no Plano Cruzado, as políticas fiscal e monetária seriam utilizadas de forma acentuada contra a inflação. $O$ intuito era diminuir o déficit público através de aumentos de tarifas, eliminação de subsídios, corte de gastos e investimentos públicos. Visando afastar o problema da defasagem dos preços públicos e administrados, como havia ocorrido no Plano Cruzado, foram decretados vários aumentos pouco antes do anúncio do congelamento: eletricidade, combustíveis, aço, telefone, entre outros (CASTRO, 2005, p. 129).

O lado heterodoxo, por sua vez, caracterizou-se por um congelamento de salários no patamar vigente quando do anúncio do Plano, a ser realizado em três fases: a) congelamento total por três meses; b) flexibilização do congelamento; e) descongelamento. Os salários ficavam indexados a uma nova base: a Unidade de Referência de Preços - URP, que era prefixada de três em três meses a partir da taxa de inflação média dos três meses

\footnotetext{
${ }^{4}$ Esclarece Eduardo Modiano (1999, p. 55), que de acordo com o novo esquema instituído a partir da URP - Unidade de Referência de Preços, a cada três meses seriam pré-fixados os percentuais de reajuste para os três meses subsequentes, tendo como base a taxa de inflação média dos três meses precedentes. Os preços também foram congelados pelo prazo máximo de 3 meses, contudo, antes foram anunciados diversos aumentos para os preços públicos e administrados, ou seja, a mesma falha apontada no Plano Cruzado.

5 Ortodoxia: conforme o pensamento ortodoxo, a inflação é decorrente do processo de emissão monetária devido aos déficits públicos, o que eleva a demanda e força a alta de preços. Desse modo, para combater a inflação, deve-se estancar a emissão de moeda, o que só é possível com a retração da demanda, quer do setor privado, pelo aumento de impostos, quer do setor público, com a redução nos gastos públicos. O combate inflacionário é alcançado através de uma política recessiva (GREMAUD; VASCONCELLOS; TONETO JUNIOR, 2009, p. 432).

${ }^{6}$ Heterodoxia: para estes, a inflação não é oriunda de excesso de demanda provocado pela emissão monetária. A emissão monetária é encarada mais como uma decorrência da inflação do que uma causa. Sendo assim, a inflação poderia se vencida sem se recorrer ao controle de demanda, ou seja, não haveria necessidade de uma política recessiva. O congelamento de preços e salários é um exemplo de medida (política de renda) característico dessa corrente(GREMAUD; VASCONCELLOS; TONETO JUNIOR, 2009, p. 432).
} 
anteriores. Com o fim de combater o gatilho salarial, sem, contudo, ensejar uma crise política, foi introduzido, através da URP, um projeto em que se garantia a correção mensal, e, ao mesmo tempo, aumentava-se a defasagem entre a inflação do mês e seu repasse para os salários. A taxa de câmbio não foi congelada para evitar a deterioração das contas externas, como ocorreu no Plano Cruzado (CASTRO, 2005, p. 129).

Contrariamente ao ocorrido com o Plano Cruzado, o plano em discussão encontrou a economia já em processo de desaceleração e buscou estabilizá-la através da redução dos salários reais e da manutenção de altas taxas de juros e elevada taxa real de câmbio. Dadas às consequências do congelamento ocorrido durante o Plano Cruzado, os comerciantes desenvolveram técnicas para furtar-se dos efeitos do controle de preços. Como já era esperada uma reedição da medida, os preços foram fixados em níveis muito altos, com descontos no ato da compra. Quando o congelamento retornou, as tabelas de comercialização não exprimiam a realidade dos preços, que estavam absolutamente superiores ao valor real. Além dessa técnica, também teve grande destaque a "maquiagem". A embalagem dos produtos era alterada para oferecer o mesmo conteúdo com quantidades distintas, ou a venda do mesmo produto com qualidade inferior.

Em outubro de 1988 foi promulgada a nova Constituição Brasileira, transferindo ao Congresso parte da responsabilidade pela condução da política econômica. E em novembro de 1988 foi entabulado um acordo inédito entre governo, iniciativa privada e trabalhadores, instituindo uma nova modalidade de redutor, através da pré-fixação dos reajustes de preços, é o nascimento do pacto social, que conseguiu reprimir, embora temporariamente, a ameaça de hiperinflação e promoveu o fim da URP salarial.

\subsection{Plano Verão}

A O fracasso do Plano Bresser dá ensejo ao surgimento do Plano Verão, com nova tentativa de congelamento de preços, salários e tarifas. $\mathrm{O}$ Plano Verão foi instituído pelo Ministro Maílson da Nóbrega, terceiro Ministro do Governo Sarney, por meio da Medida Provisória $n^{0} 32$, de 15 de janeiro de 1989, posteriormente convertida na Lei $n^{0} 7.730 / 1989$. Em seguida vieram as Medidas Provisórias $n^{0}$ 38, de 03 de fevereiro de 1989, e 40, de 08 de março de 1989, e a Lei $n^{\circ} 7.738$, de 09 de março de 1989. Houve uma radicalização das propostas de indexação. 
O congelamento de preços foi estabelecido por prazo indeterminado. Uma nova moeda foi criada, o Cruzado Novo. Foram estabelecidas regras de desindexação da economia (art. 13), proibiu-se a correção monetária para o futuro (art. 15, $\S 4^{\circ}$ ) e para os contratos em curso. Retornou a tablita, no intuito de deflacionar contratos que englobavam previsão de reajuste ao longo de sua execução.

Assim como os planos anteriores, o Plano Verão foi alvo de questionamento nos Tribunais, tanto em razão da utilização da tablita, por violar o ato jurídico perfeito e o direito adquirido, como em razão da constitucionalidade da ação do Estado sobre o domínio econômico. Os Tribunais, mais uma vez, entenderam que as medidas impostas pelo governo estavam envoltas de legalidade e constitucionalidade, haja vista que as normas de conteúdo econômico, de ordem pública, são de aplicação imediata e, portanto, alcançam os contratos em curso (AGUILLAR, 2012, p. 181).

No enfoque de Maria Anita dos Anjos (2002, p. 20), as políticas de estabilização implementadas nos planos Cruzado, Bresser e Verão, não conseguiram alcançar a sustentação da estabilidade a longo prazo. Pelo contrário, reforçaram as atitudes defensivas dos agentes econômicos, os quais esperavam não ser mais ser surpreendidos com políticas heterodoxas, que implicavam em congelamentos dos preços e salários, quebra de contratos, mudança de moeda, alteração das regras de indexação, entre outras.

Pode-se dizer que uma sucessão de erros de elaboração e condução levou o Plano Cruzado ao fracasso. Os Planos Bresser e Verão ao tentar consertar as falhas anteriores, também não obtiveram êxito, em grande parte devido a falta de apoio político. Constata-se que nos três Planos, logo após o anúncio das medidas a inflação recuava, porém, após breves períodos, se acelerava novamente, e sempre com maior intensidade. Tal panorama se deve ao não enfrentamento pelo governo dos problemas estruturais da economia, somado ao desequilíbrio das contas do governo, a política monetária dominantemente acomodatícia, ao setor empresarial que passou a se defender com maior agilidade e eficácia ante as defasagens dos preços em relação aos custos, aos trabalhadores que de modo crescente manifestavam a insatisfação quanto ao poder de compra dos salários. Diante desse cenário o governo promoveu apenas desindexações e, em seguida, administrou as inevitáveis acelerações da inflação. 


\subsection{Plano Collor}

A primeira metade dos anos 1990 é marcada no país pela posse do primeiro presidente eleito pelo voto direto, o que não ocorria desde 1960. A inflação havia ultrapassado $80 \%$ ao mês e a economia, que havia crescido a uma taxa média por volta de 7\% entre 1930-1980, estava estacionada há uma década. Fernando Collor de Mello foi eleito em uma operação de marketing eleitoral sem precedentes na história do Brasil.

Apoiado a princípio por um partido sem expressão (Partido da Reconstrução Nacional - PRN), a candidatura de Fernando Collor de Mello conseguiu se sobrepor as pretensões de políticos tradicionais, como Leonel Brizola (Partido Democrático Trabalhista - PDT), e o futuro presidente do Brasil, Luiz Inácio Lula da Silva (Partido dos Trabalhadores - PT). Collor embasava seu discurso na luta contra a corrupção, assistência às camadas sociais mais desarrimadas e promessas de profundas reformas estruturais. Todavia, assim como o governo anterior a preocupação básica do governo Collor também era o combate à inflação.

A experiência acumulada durante o governo Sarney e os insucessos dos planos de estabilização anteriores permitiram o surgimento de novos diagnósticos sobre a natureza da inflação brasileira, bem como sobre os motivos de fracasso das tentativas adotadas. Além do diagnóstico tradicional de descontrole monetário e fiscal, uma corrente de pensamento começou a ganhar cada vez mais força: "o insucesso dos choques anti-inflacionários do governo Sarney devia-se à elevada e crescente liquidez dos haveres financeiros não monetários" (GREMAUD; VASCONCELLOS; TONETO JUNIOR, 2009, p. 436).

Fernando Collor de Mello, um dia antes de assumir o governo, estabeleceu o quinto programa de estabilização econômica da Nova República, assinado por Sarney, que viria a se chamar Plano Brasil Novo. Entretanto, o nome que caiu no gosto da população foi Plano Collor. Para Lavínia Barros de Castro (2005, p. 142):

As reformas propostas por Collor, de fato, introduziram uma ruptura com o modelo brasileiro de crescimento com elevada participação do Estado e proteção tarifária, ainda que, na prática, a abertura comercial e financeira, bem como o processo de privatização, apenas deram seus primeiros passos no período de 1990-1994. A política industrial também ficou abaixo 
dos objetivos traçados, sempre subordinada à questão prioritária do combate a inflação. Já os planos econômicos Collor I e II não apenas fracassaram em eliminar a inflação, como resultaram em recessão e perda de credibilidade das instituições de poupança.

É um consenso que o Plano Collor caracterizou-se por ser o mais duramente interventivo no mercado econômico. O que mais chama atenção é que se originou do primeiro Presidente eleito com discurso declaradamente neoliberal na economia. Fernando Collor assumiu a presidência em 15 de março de 1990, e editou a Medida Provisória $n^{\circ}$ 168, depois convertida na Lei $\mathrm{n}^{\circ} 8024 / 1990$, modificou a moeda cruzado novo para cruzeiro e retirou de circulação por 18 meses, todos os depósitos do sistema financeiro que ultrapassassem $\$ 50.000$ cruzados novos. Referidos valores bloqueados permaneceriam à disposição do Banco Central e voltariam a seus poupadores após 16 de setembro de 1991, em 12 parcelas mensais. Seja qual fosse a modalidade de depósito mantido, passaria a fazer parte de um depósito legal mantido junto ao Banco Central, o qual poderia se dispor dos valores com a condição de remuneração de $06 \%$ ao ano e correção monetária, durante aquele período (AGUILLAR, 2012, p. 182).

Para Gremaud, Vasconcellos e Toneto Junior (2009, p. 440), o confisco da liquidez parece ter sido a grande âncora do plano. Objetivou-se retomar a capacidade de fazer política monetária ativa congelando o estoque de moeda. O resultado imediato foi uma enorme desestruturação do sistema produtivo com corte nas encomendas, semiparalisia na produção, demissões, férias coletivas, redução nas jornadas de trabalho, redução nos salários, deflação, atraso nos pagamentos de dívidas, expansão no volume e no prazo dos créditos comerciais, desenvolvimento de meios de pagamento alternativos. Esse choque sobre os estoques monetários acarretou profunda desestruturação em termos de condições de emprego e de produção, gerando uma retração do PIB da ordem de 8\% no segundo trimestre de 1990. Em relação ao controle da liquidez nota-se que houve grande preocupação com o estoque e não com o fluxo.

Não foi implantada tabela de conversão para o chamado "confisco" de cruzados. O dólar oficial não foi congelado e o câmbio foi liberalizado. $\mathrm{O}$ ágio do mercado paralelo baixou de $111 \%$ para $39 \%$, retornando posteriormente para $60 \%$. A Bolsa de Valores baixou muito em consequência das medidas recessivas (BRITO, 2004, p. 27). 
O Plano Collor, ou "Brasil Novo", foi acompanhado de um pacote de medidas que somava mais de duas dezenas de decretos e Medidas Provisórias. Ao privar os cidadãos e a iniciativa privada do acesso aos seus recursos, não podia ser diferente, a medida encampada pelo governo causou um alarde nacional. Sob o fundamento de que os bloqueios configuravam confisco ou empréstimo compulsório sem satisfazer às formalidades legais, os juízes passaram a deferir os mandados de segurança para liberação dos valores. Igualmente, entendeu o Judiciário que o contrato de depósito realizado entre a instituição financeira e o cliente havia sido rompido por ato governamental, de modo que feria o ato jurídico perfeito, conforme dispõe o art. $5^{\circ}$, XXII, da Constituição Federal.

O bloqueio de recursos também feria o direito de propriedade, pois impossibilitava o titular do crédito o direito de movimentá-lo livremente. Em sua defesa, o governo alegou que no que se refere ao direito de propriedade a lei prevê que o legislador tem a possibilidade de redefinir o conteúdo do núcleo ou âmbito de proteção ou, até mesmo, optar pela determinação de outras limitações a esse direito. Segundo Fernando Herren Aguillar (2012, p. 182), "filas enormes se formavam em frente à Justiça Federal de cada capital, para distribuir ações". Os escritórios de advocacia expandiram exitosamente ou conseguiram seu impulso inicial apenas com as ações de desbloqueio de cruzados novos.

Em meio às ações judiciais, o governo editou a Medida Provisória $\mathrm{n}^{\mathrm{o}}$ 173, em 18 de março de 1990, proibindo a concessão de liminar em mandado de segurança e em ações ordinárias e cautelares oriundas das Medidas Provisórias 151, 154, 158, 160, 161, 162, 164, 165, 167 e 168. No mês seguinte, respectivamente nos dias 17 e 23, Fernando Collor editou mais duas novas Medidas Provisórias, 181 e 182, reiterando a proibição contida na MP 173, desta vez referindo-se propriamente às leis que haviam convertido as medidas provisórias protegidas. No intuito de atacar as Medidas Provisórias 173, 181 e 182, foram propostas três Ações Diretas de Inconstitucionalidade ( $n^{\circ}$ s 223, 272 e 273), porém, nenhuma delas obteve êxito.

Ao completar um ano de plano, em janeiro de 1991, o governo havia equilibrado as finanças públicas e as reservas externas haviam aumentado para 8,5 bilhões de dólares. Porém, o país ingressava em uma recessão 
profunda ${ }^{7}$. O PIB baixou aproximadamente 4\% em 1990, mais de um milhão de pessoas estavam desempregadas e a inflação retornava ao patamar de $20 \%$ ao mês (BRITO, 2004, p. 27).

Dado o fracasso do Plano Collor, uma nova tentativa heterodoxa foi posta em prática, com a Lei $\mathrm{n}^{\circ} 8.177$, de $1^{\circ}$ de março de 1991, denominada Plano Collor II. O novo pacote instituía regras para a desindexação, eliminando o Bônus do Tesouro Nacional (BTN) e outros índices monetários. Surgiram novas regras para a acomodação dos contratos em curso. Porém, mais uma vez o modelo estabelecido foi inábil para reprimir a elevação acelerada dos preços. O Plano Collor II era principalmente uma reforma financeira com o fim de acabar com o overnight e outras formas de indexação e um congelamento de preços e salários.

Somente em junho de 1991 foi proposta pelo PSB perante o Supremo Tribunal Federal Ação Direta de Inconstitucionalidade, de $n^{0} 534$, contra o bloqueio dos cruzados em razão do Plano Collor I. A alegação era de que a medida configurava empréstimo compulsório, sem, contudo, se atentar para os limites e pressupostos constitucionais previstos no art. 148. Por maioria de votos o STF entendeu que o ajuizamento da ADI fora tardio, ou seja, o lapso temporal transcorrido desde a edição do ato normativo até a propositura da medida judicial inviabilizava a concessão da medida cautelar, impedindo o reconhecimento da situação configuradora do periculum in mora, embora restasse reconhecido o relevo jurídico da tese postulada. Como a ação principal da referida ADI $n^{\circ} 534$ só foi inclusa na pauta de votação um ano após sua propositura, quando faltavam apenas alguns dias para a última parcela de devolução dos cruzados bloqueados, o Supremo Tribunal Federal julgou a ação improcedente por unanimidade.

Mesmo com as medidas de contenção dos gastos públicos e controle da inflação, está não cedeu. Após uma série de escândalos, esquemas de corrupção e dois planos econômicos fracassados, Fernando Collor de Mello foi deposto através do impeachment, em 29 de dezembro de 1992. Itamar Franco assumiu como novo Presidente da República e dando continuidade ao processo de reformas, lançou as bases do programa de estabilização que finalmente encerraria os 30 anos de indexação da economia nacional, iniciada em 1964 com a criação da ORTN. A partir da criação da Unidade Real de Valor (URV) em meados de 1994, a desindexação se tornou uma realidade.

\footnotetext{
Aperto monetário.
} 


\subsection{Plano Real}

Como se pôde perceber até aqui, a crise financeira do Estado brasileiro foi se agravando em razão dos sucessivos fracassos no combate à inflação. O período de 1986 a 1991 ficou marcado por nada menos que cinco choques na economia (Plano Cruzado, Plano Bresser, Plano Verão, Plano Collor I e Plano Collor II). Enquanto o país se debatia para acabar com a inflação, a indústria deixou de acompanhar os avanços tecnológicos e organizacionais exigidos pelo mercado.

Da mesma forma que o Plano Cruzado, o Plano Real também partiu do diagnóstico de que a inflação brasileira possuía caráter inercial. Como enfatizado anteriormente, o debate entre os inercialistas ${ }^{8}$, antes do Plano Cruzado, havia resultado em dois tipos de propostas para combate à inflação: i) o choque heterodoxo (Francisco Lopes) ${ }^{9}$, que se fundava no congelamento de preços, e ii) a reforma monetária (Larida ${ }^{10}$, que correspondia à simulação dos efeitos de uma hiperinflação com o convívio de duas moedas, uma boa e outra ruim, com a primeira substituindo a última ao longo do tempo. O Plano Cruzado adotou a primeira proposta e não obteve êxito em razão do tempo excessivo de congelamento, da explosão de demanda após a implantação do plano e dos impactos do setor externo. O Plano Real adotou a proposta Larida (GREMAUD; VASCONCELLOS; TONETO JUNIOR, 2009, p. 448).

A primeira medida para concretização do Plano Real foi dada no governo Itamar Franco, com a edição da Medida Provisória nº 336, em 28

\footnotetext{
${ }^{8} \mathrm{O}$ fundamento teórico no qual se baseiam os inercialistas é o estruturalismo que distingue os fatores estruturais e os mecanismos de propagação da inflação. Os inercialistas separam o processo inflacionário em "choque" e "tendência", com atenção para o segundo elemento. A ideia básica é que, a partir de determinado momento, a inflação adquire certa autonomia, ou seja, assume um comportamento inercial, em que a inflação do período passado determina a inflação atual, que determinará a inflação futura, e assim por diante. Essa inércia decorre dos mecanismos de indexação - correção monetária de preços, salários, câmbios e ativos financeiros, que tendem a reproduzir a inflação passada para o futuro. Na falta de choques, a inflação continuaria no patamar vigente, isto é, uma taxa de inflação estável (GREMAUD; VASCONCELLOS; TONETO JUNIOR, 2009, p. 420).

${ }^{9} \mathrm{O}$ Choque heterodoxo (Lopes) pode ser dividido em duas fases: a) um congelamento rigoroso de preços pelo período de 06 meses; e b) um período de descompressão com variações de até 1,5\% para restabelecer preços relativos, que perduraria por 18 meses (GREMAUD; VASCONCELLOS; TONETO JUNIOR, 2009, p. 420).

${ }^{10}$ Moeda indexada (Larida): se objetiva a desindexação da economia através da indexação total, ou seja, provoca-se um encurtamento dos períodos de reajuste de modo a tornar as rendas reais insensíveis à taxa de inflação doméstica e permitir uma sincronização perfeita dos reajustes. Seria possível com a modificação da unidade de conta na economia, por exemplo, ligando os preços ao dólar (GREMAUD; VASCONCELLOS; TONETO JUNIOR, 2009, p. 420).
} 
de julho de 1993, posteriormente convertida na Lei $\mathrm{n}^{\circ} 8.697$, de 27 de agosto de 1993, que modificou novamente a unidade monetária brasileira, desta vez para "Cruzeiro Real".

O Plano Real dividiu o enfretamento do processo inflacionário em três fases: i) ajuste fiscal (ortodoxa); ii) indexação completa da economia (heterodoxa) - Unidade Real de Valor (URV); e iii) reforma monetária transformação da URV em reais.

$\mathrm{O}$ ajuste fiscal, posto em prática na primeira fase, objetivava equacionar o desequilíbrio orçamentário para os próximos anos e evitar que surgissem pressões inflacionárias. $\mathrm{O}$ ajuste se fundava em três elementos: corte de despesas, aumento dos impostos e diminuição nas transferências do governo federal (GREMAUD; VASCONCELLOS; TONETO JUNIOR, 2009, p. 449-453).

A segunda fase, correspondente a um novo sistema de indexação, iniciou-se no final de fevereiro de 1994. O governo criou a Unidade Real de Valor - URV, cujo valor em cruzeiros reais seria corrigido diariamente pela taxa de inflação medida pelos principais índices (IGP-M, IPC-FIPE e IPCAEspecial), que passaria a funcionar como unidade de conta no sistema. $\mathrm{O}$ valor da URV, nessa fase, manteria uma paridade fixa de um para um com o dólar, isto é, seu valor seria a própria taxa de câmbio. A Unidade Real de Valor (URV) foi instituída pela Medida Provisória $n^{\circ}$ 434, de 28 de abril de 1994. A finalidade era criar uma transição para a futura moeda, o real (terceira fase). A URV seria como um padrão estável para os preços, de modo que os agentes de mercado adquirissem confiança quanto à sua capacidade de refletir o valor dos bens e serviços (GREMAUD; VASCONCELLOS; TONETO JUNIOR, 2009, p. 449-453).

Uma série de preços e rendimentos foi convertida instantaneamente em URV ${ }^{11}$, e os demais preços foram sendo convertidos voluntariamente pelos agentes. Instituiu-se um sistema bimonetário em que a URV funcionava como unidade de conta, representando o preço das mercadorias, porém, as transações eram liquidadas em cruzeiro real, que desempenhava o papel de meio de troca. Desse modo, a inflação permanecia na moeda em circulação (CR\$), e não na unidade de conta, cujo valor era corrigido pela própria inflação da moeda ruim. Essa técnica possibilitou o processo de ajustamento dos preços relativos, que equivalia ao objetivo dessa fase, a fim de evitar

\footnotetext{
${ }^{11}$ Preços oficiais, contratos, salários, impostos, etc.
} 
choques posteriores (GREMAUD; VASCONCELLOS; TONETO JUNIOR, 2009, p. 449-453).

A terceira fase, adoção da moeda Real (R\$), foi posta em prática quando praticamente todos os preços estavam expressos em URV. Em $1^{\circ}$ de julho o governo introduziu a nova moeda, cujo valor era igual ao da URV e ao US\$ do dia: CR \$2.750,00. Todos os preços em CR \$ eram convertidos em R\$, dividindo-se pelo valor da URV do “dia D”. Logo após a conversão, houve uma aceleração inflacionária pela tentativa de alguns agentes de elevar seus preços, tanto por receio de algum congelamento quanto para tentarem tirar proveito na renda. Todavia, essa pressão inflacionária rapidamente se retraiu, visto que não havia condições para sustentar os preços mais elevados. A moeda "Real" passou a desempenhar três funções básicas: meio de pagamento, denominador comum de valores e reserva de valor. A execução do Plano Real buscou evitar o erro dos demais choques heterodoxos, ou seja, a febre do consumo, decorrente do aumento do poder aquisitivo e a grande expansão do crédito (GREMAUD; VASCONCELLOS; TONETO JUNIOR, 2009, p. 449-453).

Em pouco tempo o Plano Real conquistou o mercado, que foi se adaptando à nova moeda. Aos poucos, a inflação foi diminuindo, de $40 \%$ ao mês, até alcançar índices aceitáveis de $10 \%$ ao ano. O resultado deste sucesso é reflexo da divulgação antecipada, da negociação pública com o Congresso e do ajuste de preços relativos, fatores que trouxeram segurança e previsibilidade ao mercado (BRITO, 2004, p. 30).

Não há dúvidas de que o Plano Real foi o único que obteve sucesso no controle da inflação no Brasil após 1980. Os planos de estabilização anteriores fracassaram embora imbuídos de grandes esforços governamentais, provavelmente por insistirem na técnica de congelamento, que se mostrou reiteradamente ineficiente e lesiva, na imposição de medidas sem discussão e no desequilíbrio dos preços relativos. Reviver os planos de estabilização nacional permite dizer que o Brasil aprendeu com seus erros e avançou.

\section{JURIDICIDADE DOS PLANOS ECONÔMICOS}

A ideologia econômica praticada por um Estado (Estado Liberal, Estado Social ou Novo liberalismo) reflete o grau de participação dos governos na economia. Sob esse aspecto, é de se dizer que as políticas e 
planos econômicos públicos são dotados de uma certa juridicidade, conforme pensamento de Laubadére analisado pelo Prof. João Bosco Leopoldino da Fonseca (2004, p. 252):

[...] é necessário reconhecer ao Plano uma certa juridicidade, porque, se se afirma que o plano não pertence à ordem, ao contexto jurídico, não se lhe podem atribuir efeitos jurídicos. Ficará então destituído de qualquer utilidade, porque não se prestará a um controle administrativo da economia, e com ele não poderá ser questionada a responsabilidade do Estado.

Ao se referir a uma "certa" juridicidade seria, então, possível classificar os planos econômicos públicos conforme o grau de intervenção sobre as relações econômicas, admitindo-se, em qualquer deles, uma juridicidade mínima? E a partir dessa classificação seria possível defender a responsabilização do Estado por dano decorrente de planejamento econômico?

Almiro do Couto e Silva (2004b, p. 135-136), ao tratar do tema em trabalho intitulado "Problemas Jurídicos do Planejamento" concluiu que o Estado não pode deixar de indenizar quando acarreta dano ao administrado em decorrência dos planos a que se obrigara, apresentando três classificações de planos a partir do critério de força vinculativa de que são dotados: i) planos indicativos; ii) planos incitativos; e iii) planos imperativos, com as características a seguir delineadas.

Indicativos são aqueles em que não há obrigatoriedade para os administrados, ou seja, a política econômica adotada pelo governo apenas sugere determinada direção, sem objetivar abertamente a participação da iniciativa privada. Não há nessa modalidade qualquer cogência por parte do Estado ou o oferecimento de vantagem concreta a fim de influenciar as decisões.

Já os incitativos ou estimulativos, são aqueles onde o governo destaca a política econômica no intuito de alcançar o engajamento da iniciativa privada para consecução de seus interesses. É comum nessa modalidade de plano que além da indicação da política econômica o governo prometa medidas e incentivos no caso de cooperação da iniciativa privada. Ou seja, o Estado busca obter dos particulares uma forma de atuar e de proceder que ajustese com os objetivos estabelecidos no plano. 
Como se pode perceber, no caso dos incitativos o administrado adere à política econômica sob o manto da confiança e boa-fé da administração. Desse modo, a responsabilização do Estado dependerá daquilo que já tiver sido efetivado, bem como dos prejuízos decorrentes de eventuais modificações.

Os imperativos, como o próprio nome já diz, são planos em que não há escolha aos administrados, devem ser obrigatoriamente observados. É o caso dos planos de estabilização econômica adotados no Brasil durante a década de 80 e 90 (Plano Cruzado; Plano Bresser; Plano Verão; Plano Collor; e Plano Real - que pode ser considerado incitativo em parte em razão da URV).

No caso dos imperativos os particulares ficam sujeitos às regras do plano e são obrigados a uma determinada conduta, sob pena, inclusive, de aplicação de sanções administrativas e, até mesmo, criminais. Nota-se com a classificação de Almiro do Couto e Silva que a questão concentra-se em estabelecer, no caso concreto, a conduta estatal, a conduta do lesado - caso haja excludentes, e o dano causado.

Tanto nos incitativos como nos imperativos pode haver responsabilidade estatal e, também, nos meramente indicativos, mandatórios para a pessoa pública. Para confirmar o raciocínio imprescindível o exame do conteúdo do art. 174 da Constituição da República, que ora reproduzimos:

Art. 174. Como agente normativo e regulador da atividade econômica, o Estado exercerá, na forma da lei, as funções de fiscalização, incentivo e planejamento, sendo este determinante para o setor público e indicativo para o setor privado.

Analisando a questão, Lúcia Valle Figueiredo (2002, p. 13), que também defende a possibilidade de responsabilização do Estado por danos oriundos da atividade planificadora, salienta que "mesmo em governos com preocupação social marcada, como determina a Constituição Brasileira, não se poderia justificar mudanças descriteriosas a pretexto, à invocação do interesse público, chamado a contexto sem qualquer suporte".

Em outra ocasião, versando sobre o mesmo tema, Lúcia Valle Figueiredo (2004, p. 286), considerou o pensamento de Jesús Gonzales Perez em sua obra intitulada "El Principio de la Buena Fe", defendendo que o administrado tem o direito de confiar na administração. É dizer, planos são 
elaborados sem a necessária previsão das consequências, tanto é assim que são modificados em brevíssimo prazo, sem se levar em consideração os graves prejuízos impostos à iniciativa privada.

O planejamento estatal, ainda que seja encarado sob o manto da discricionariedade administrativa, também está sujeito obrigatoriamente aos mecanismos de controle para fins de averiguação de sua conformidade com as inafastáveis regras constitucionais.

\section{RESPONSABILIDADE EXTRACONTRATUAL DO ESTADO E SEGURANÇA JURÍDICA}

Entre as diversas formas de descrever o Direito, parte-se de uma perspectiva objetiva que permite afirmar que a Ciência Jurídica constitui a arte de regular o comportamento humano. A Economia, ao contrário, pode ser compreendida como a ciência que estuda o modo que o ser humano toma decisões e se comporta em um mundo de recursos escassos e suas consequências.

Falar da relação entre Direito e Economia é, portanto, fazer uma Análise Econômica do Direito. Segundo Ito Gico Junior (2011, p. 17), a Análise Econômica do Direito (AED), é o palco do conhecimento humano que tem como alvo empregar os diversos instrumentos teóricos e empíricos econômicos e das ciências afins para ampliar a compreensão e o alcance do direito e aperfeiçoar o desenvolvimento, a aplicação e a avaliação das normas jurídicas, principalmente com relação às suas consequências.

Sob esse ponto de vista, os agentes agem no mercado de acordo com uma racionalidade maximizadora em relação aos custos e benefícios. E este comportamento racional é o responsável pelo equilíbrio do mercado. Um mercado em equilíbrio evita desperdícios, é um mercado eficiente. Portanto, a interação entre Direito e Economia é extremamente relevante no que se refere à eficiência, haja vista que o resultado das decisões tomadas na seara jurídica tem reflexo direto na melhor ou pior alocação dos recursos disponíveis, ou seja, no equilíbrio do mercado (GICO JUNIOR, 2011, p. $30)$.

A eficiência, enquanto princípio aproxima-se muito da ideia de economicidade. Para se atingir os objetivos econômicos o Estado deve se concentrar na relação custo-benefício da política adotada. É tarefa dos 
governos agir em conformidade com o ordenamento jurídico, com a moral administrativa e com o princípio da boa-fé. A Economia e o Direito devem servir de instrumento para indicar a atuação administrativa na medida em que compõem um instrumento que funciona como um conjunto de alternativas que levem a um maior alcance dos fins pretendidos.

O Estado deve estar voltado para o atingimento de finalidades voltadas ao bem estar da coletividade e, consequentemente, desse seu atuar podem derivar danos que muitas vezes são inevitáveis para o alcance de certos fins. Assim, a lesão de um direito particular, embora praticado em nome de um interesse público, não deixa de merecer reparação. Ou seja, o Estado deve ser responsável pelo resultado prejudicial dos atos praticados.

A questão que se pretende levantar com esta discussão é se determinada política econômica, sob suspeita de violar direitos e garantias será ou não conciliável com a Constituição, no sentido de atendimento aos princípios da razoabilidade, proporcionalidade e motivação (FIGUEIREDO, 2002, p. 17). A intenção é demonstrar a necessidade de controle da discricionariedade dos atos políticos de planejamento econômico, ocupando a responsabilização lugar de destaque no tratamento desse assunto.

A responsabilidade extracontratual objetiva do Estado da forma como hoje é conhecida consagrou-se somente na Constituição de 1946. A referida Carta Constitucional já estabelecia o dever de ação regressiva contra o funcionário que tivesse agido com dolo ou culpa. No mesmo sentido foi a redação da Constituição de 1967 ao delinear a responsabilidade objetiva, que sempre esteve acolhida em nossos Tribunais (FIGUEIREDO, 2004, p. 267-268). No caso da Constituição da República de 1988, cabível à análise da redação do art. $37, \S 6^{\circ}$ : “as pessoas jurídicas de direito público e as de direito privado prestadoras de serviços públicos responderão pelos danos que seus agentes, nessa qualidade, causarem a terceiros, assegurado o direito de regresso contra o responsável nos casos de dolo ou culpa".

O texto constitucional enfatiza que a responsabilidade é objetiva não só em relação ao Estado, mas também em relação àqueles que exercem funções estatais. O prejuízo de que trata o referido dispositivo não decorre de ato ilícito, trata-se de responsabilidade oriunda da teoria do risco administrativo, que não exige ilicitude na ação administrativa causadora de dano. O nexo de causalidade entre o dano sofrido e a conduta da Administração implica no inescusável dever de indenizar. 
A responsabilidade extracontratual é, portanto, oriunda da inobservância de regras atinentes a direitos pessoais ou reais, não sendo necessário vínculo anterior para configurá-la, sendo suficiente apenas que haja um dever contido em uma norma legal e que a afronta a este dever ocasione prejuízos (JUSTEN FILHO, 2005, p. 794). Poderão ser incluídas nesta categoria a intervenção normativa, fiscalizadora, de incentivo, de planejamento e de planos econômicos, nos termos do art. 174 da CF/88.

Especificamente quanto à responsabilidade objetiva do Estado no caso de dano decorrente de planos econômicos, impõe esclarecer que havendo participação do administrado nos planos não há como eximir o Estado de sua responsabilidade, seja por atos oriundos de mudanças na planificação, portanto responsáveis e lícitos, seja por atos irresponsáveis, que ocorrem em grande parte das vezes em países cujo grau de responsabilização dos governantes ainda é nulo ou pouco aplicado (FIGUEIREDO, 2004, p. 269). Ao serem elaborados os planos econômicos, é tarefa dos governos conciliar os interesses da sociedade com os da iniciativa privada, uma vez que, juntos, permitem identificar o interesse coletivo.

Essa relação necessária de aproximação exige de todos envolvidos, além do respeito à ordem jurídica, a confiança e a boa-fé, de modo que as empresas possam confiar na política econômica em relação a qual não tem alternativa de escolha e a partir dela definir seus objetivos e estratégias de negócios com segurança jurídica.

Antonio-Enrique Pérez Luño (1994, p. 24-27), entende que a segurança constitui um desejo arraigado na vida do homem, que sente terror ante a insegurança de sua existência, a imprevisibilidade e a incerteza em relação ao que está submetido. Assim, a segurança é uma das necessidades humanas básicas que o Direito deve satisfazer. Todavia, a segurança enquanto valor jurídico não é algo que se dê espontaneamente, e com idêntico sentido e intensidade nos diferentes sistemas normativos. Sua função e alcance dependerão das lutas políticas e das questões culturais de cada sociedade. Para Pérez Luño, no Estado de Direito a segurança jurídica assume dois perfis: a) um de pressuposto do Direito, mas não de qualquer forma de legalidade positiva, e sim daquela que emana dos direitos fundamentais; $b$ ) e outro de função do Direito, assegurando a realização das liberdades. Desse modo, a segurança jurídica além de não correr o risco de manipulação, se converte em um valor jurídico indispensável para a conquista dos demais valores que compõem a ordem jurídica constitucional. 
A discussão contemporânea sobre direito e desenvolvimento possivelmente está em seu período mais plural. A possibilidade de criar instituições que garantam segurança jurídica sem recair em fórmulas padronizadas parece estar amplamente aberta. A contenda do papel da regulação privada e do mundo privado como um todo é imprescindível na produção da segurança jurídica. De modo clássico, “a segurança jurídica é vista como uma espécie de serviço público que o Estado deve fornecer à sociedade com a construção de um bom sistema de justiça" (RODRIGUEZ, 2011, p. 40). A dúvida é se esta concepção consegue abarcar todos os aspectos envolvidos, ou seja, os contratos em execução e a autorregulação dos mercados.

No direito contemporâneo brasileiro a segurança jurídica é entendida, segundo Almiro do Couto e Silva (2004a, p. 36):

Como sendo um conceito ou um princípio jurídico que se ramifica em duas partes, uma de natureza objetiva e outra de natureza subjetiva. A primeira, de natureza objetiva, é aquela que envolve a questão dos limites à retroatividade dos atos do Estado até mesmo quando estes se qualifiquem como atos legislativos. Diz respeito, portanto, à proteção ao direito adquirido, ao ato jurídico perfeito e à coisa julgada. Diferentemente do que acontece em outros países cujos ordenamentos jurídicos frequentemente têm servido de inspiração ao direito brasileiro, tal proteção está há muito incorporada à nossa tradição constitucional e dela expressamente cogita a Constituição de 1988, no art. $5^{\circ}$, inciso XXXVI. A outra, de natureza subjetiva, concerne à proteção à confiança das pessoas no pertinente aos atos, procedimentos e condutas do Estado, nos mais diferentes aspectos de sua atuação.

Modernamente, no direito comparado, a doutrina prefere admitir a existência de dois princípios distintos, apesar das estreitas correlações existentes entre eles. Falam os autores, assim, em princípio da segurança jurídica quando designam o que prestigia o aspecto objetivo da estabilidade das relações jurídicas, e em princípio da proteção à confiança, quando aludem ao que atenta para o aspecto subjetivo.

Confirma-se que os princípios da segurança jurídica e da proteção à confiança são meios conservadores implantados na ordem jurídica, dedicados à manutenção do status quo e a impedir que os administrados sejam surpreendidos por modificações do direito positivo ou na conduta do Estado. Para manter o equilíbrio do mercado há mecanismos que obrigam, formal 
ou informalmente, o cumprimento de regras e que reafirmam valores. $\mathrm{O}$ setor privado atua sob o espectro do lucro, preocupando-se com a continuidade de suas relações comerciais. A tendência é que o Estado se comporte de forma precavida frente à autorregulação, substituindo normas interventivas por modalidades de indução de comportamentos, de modo a manter o equilíbrio econômico-financeiro e fortalecer a autorregulação.

Salienta José Rodrigo Rodriguez (2011, p. 41), que "a autorregulação pode ser pensada como um conjunto de mecanismos por meio dos quais a sociedade exerce, com maior grau de autonomia, a função de regular diversos conflitos sociais sem prescindir do Estado, mas tendo nele um agente indutor e facilitador". Portanto, a segurança jurídica se traduz em tornar as intervenções estatais cada vez mais previsíveis, conciliando os deveres do Estado e as garantias da coletividade com os fins do setor privado.

O dever de indenizar do Estado, nesta modalidade de situação, torna irrelevante o descumprimento à lei, a acordo ou até mesmo a discricionariedade do Estado. O ponto fundamental é o prejuízo causado ao particular em razão da intervenção estatal normativa no domínio econômico, uma vez que esta deve ser conjugada com os princípios da livre iniciativa e da concorrência. Diógenes Gasparini (2003), defende que as limitações da intervenção serão sempre determinadas pela principiologia constitucional, pela declaração expressa dos fundamentos do Estado Democrático de Direito, dentre eles a cidadania, a dignidade da pessoa humana, os valores sociais do trabalho e da livre iniciativa.

Ademais, o comportamento das partes envolvidas em determinada política econômica está inter-relacionado. A conduta adotada por um dos agentes modifica o cenário que se apresenta para o outro agente. Considerando-se um panorama de inexistência de regra de responsabilidade, o ofensor, nestes casos, nunca será responsabilizado por danos que eventualmente venha a causar, na medida em que não têm incentivos para tomar as medidas adequadas de precaução. Da mesma forma, a responsabilidade ilimitada do ofensor faz com que a vítima deixe de exercer a precaução adequada. Assim, uma regra eficiente deve situar-se entre estes dois extremos. Ressalte-se, contudo, que tanto quando a vítima exerce precaução, quanto quando ela não o faz, a resposta menos custosa para o ofensor é exercer a precaução (PORTO, 2012, p. 190-193). Nesse sentido, a precaução deve ser uma estratégia estritamente dominante no planejamento econômico estatal. 
Entre os aspectos econômicos importa relembrar que os planos econômicos reúnem soluções possíveis para enfrentar as crises econômicas e a escassez de recursos. Assim, quando elaborados e executados pelo Estado representam instrumentos de interferência na condução das atividades empresariais. Ou seja, os planos econômicos governamentais reúnem soluções econômicas vertidas em normas jurídicas e a normatividade jurídica desta intervenção estatal atinge as empresas, que muitas vezes são obrigadas a seguir a política econômica pública (mesmo as incitativas) para sobreviver no domínio econômico.

Neste sentido as políticas econômicas têm repercussão sobre as relações econômicas e devem ser submetidas aos controles jurídicos previstos no ordenamento jurídico. Defende-se este argumento, pois, para enfrentar as crises e desafios sociais, tecnológicos, ambientais (especialmente pós-segunda guerra), é necessário um Estado regulador, especialmente, no âmbito econômico.

A atuação empresarial representa para a sociedade externalidades negativas e positivas. A partir destas, tem-se a fonte da função social das empresas, haja vista que geram oportunidades de inovações tecnológicas, empregos, circulação de bens e serviços e lucro. Esta virtuosidade das relações econômicas depende de um ambiente econômico, político e social estável e seguro, com razoáveis graus de previsibilidade. São exemplos de condições mínimas para a sustentabilidade econômica empresarial. E, uma ordem jurídica que contribua para estes pilares, é fundamental. Desse modo, aos governos, que também são destinatários da ordem jurídica, foram atribuídos deveres e poderes jurídicos, devendo, em suas ações, proporcionar tais condições. Devem ser promotores e protetores da segurança jurídica.

Embora a questão da responsabilidade extracontratual objetiva do Estado por dano decorrente de planos econômicos não tenha recebido a adequada atenção do ordenamento jurídico brasileiro, tem-se que a partir das circunstâncias do caso concreto o dever de indenizar é cogente, e seu fundamento característico reside na quebra da confiança, com a violação de deveres da segurança jurídica decorrentes do princípio da boa fé.

\section{CONCLUSÃO}

No intuito de contribuir para o debate sobre o importante tema da responsabilidade extracontratual do Estado por danos decorrentes de 
planejamento econômico, assunto cuja aplicação ainda não está definitivamente consolidada no âmbito jurídico, esta pesquisa partiu da revisita aos planos de estabilização econômica nacional: Plano Cruzado (1986), Plano Bresser (1987), Plano Verão (1989), Plano Collor (1990) e Plano Real (1994), retratando os principais elementos destas políticas econômicas, de modo a evidenciar a imperatividade da ação interventiva do Estado.

Entre o Plano Cruzado e o Plano Real, que foi o único que obteve êxito no controle da inflação no Brasil, a economia nacional sofreu cinco grandes choques na tentativa de estabilização. O que mais chama à atenção é a reiterada adoção de políticas duramente interventivas no mercado econômico, entre elas, cita-se: a) Planos Cruzado, Bresser e Verão: congelamento dos preços e salários e quebra de contratos; b) Plano Collor: sem dúvida, o mais interventivo de todos, pois bloqueou e retirou de circulação, por 18 meses, todos os depósitos do sistema financeiro que ultrapassassem $\$ 50.000$ cruzados novos. Quanto ao Plano Real, é importante ressaltar que seu sucesso se deve ao fato de não ter insistido nas técnicas mal sucedidas utilizadas nos planos anteriores, somado a procedimentos prévios de divulgação de informações para a população, justamente para evitar problemas jurídicos.

Sob o aspecto jurídico, nos planos econômicos tais como os analisados, há grau de juridicidade ainda que possa ser considerado como ato discricionário da administração pública. Portanto, estão sujeitos aos mecanismos de controle para fins de comprovação de sua conformidade com as regras constitucionais.

Tendo em vista que o particular ao aderir ou ao ser compelido pela força coercitiva do Estado a se submeter a determinado plano econômico, o faz motivado pelo grau de juridicidade e, também, pelo princípio da confiança e da boa-fé, os prejuízos decorrentes do desrespeito aos princípios basilares da constituição econômica (art. $170 \mathrm{CF} / 88$ ), permitem discutir a responsabilização do Estado nos termos do art. $37, \S 6^{\circ}$ da CF/88.

Nem sempre a racionalidade econômica é coincidente com a racionalidade jurídica, no sentido de que muitas medidas econômicas são justificáveis à luz da economia e não são em face do interesse da coletividade. Desse modo, devem os governos motivar suas opções de políticas econômicas a fim de que possam ser controladas pelo judiciário, 
especialmente, para avaliar o respeito ao direito adquirido, à coisa julgada e ao ato jurídico perfeito.

Os argumentos apresentados querem reforçar a importância do Estado Democrático de Direito que se realiza por meio de ações públicas e privadas dirigidas conforme a Constituição. Este é o caminho para garantir o direito à reparação de danos em face de prejuízos decorrentes do descumprimento dos deveres jurídicos estatais. Ou seja, a responsabilidade do Estado por dano econômico.

Este é o controle para garantir a efetividade do Princípio da Segurança Jurídica, pressuposto cogente do ordenamento jurídico de um Estado de Direito e, portanto, imprescindível para a estabilidade e sustentabilidade dos negócios jurídicos tanto no âmbito privado quanto no âmbito público.

\section{REFERÊNCIAS}

AGUILlAR, Fernando Herren. Direito Econômico. 3.ed. São Paulo: Atlas, 2012.

ANJOS, Maria Anita dos. Retrospectiva da economia brasileira nos últimos 45 anos. Revista FAU BUSINESS, Blumenau, n.4, dez. 2002.

BRITO, Paulo. Economia brasileira: planos econômicos e políticas econômicas básicas. 2.ed. São Paulo: Atlas, 2004.

CASTRO, Lavínia Barros de. Esperança, frustração e aprendizado: a história na nova república. In: GIAMBIAGI, Fabio; VILLELA, André. Economia brasileira contemporânea: 1945-2004. Rio de Janeiro: Elsevier, 2005.

COUTO E SILVA, Almiro do. O princípio da segurança jurídica (proteção à confiança) no direito público brasileiro e o direito da administração pública de anular seus próprios atos administrativos: o prazo decadencial do art. 54 da lei do processo administrativo da União (lei n. ${ }^{\circ}$ 9.784/99). Revista da Procuradoria-Geral do Estado do Rio Grande do Sul, Porto Alegre, v.27, n.57, 2004 b. 
. Problemas jurídicos do planejamento. Revista da

Procuradoria-Geral do Estado do Rio Grande do Sul, Porto Alegre, v.27, n.57, 2004a.

FIGUEIREDO, Lúcia Valle. Curso de direito administrativo. 7. ed. São Paulo: Malheiros, 2004.

FIGUEIREDO, Lúcia Valle. O devido processo legal e a responsabilidade do Estado por dano decorrente do planejamento. Revista Diálogo Jurídico, Salvador, n. 13, abr./maio 2002. Disponível em: $<$ http:// www.direitopublico.com.br>. Acesso em: 8 fev. 2013.

FONSECA, João Bosco Leopoldino da. Direito Econômico. 5. ed. Rio de Janeiro: Forense, 2004.

GASPARINI, Diógenes. Curso de direito administrativo. 8. ed. São Paulo: Saraiva, 2003.

GICO JUNIOR, Ivo. Introdução à análise econômica do direito. In: RIBEIRO, Márcia Carla Pereira; KLEIN, Vinícius (Coord.). O que é análise econômica do direito. Belo Horizonte: Fórum, 2011.

GREMAUD, Amaury Patrick; VASCONCELLOS, Marco Antonio Sandoval de; TONETO JUNIOR, Rudinei. Economia brasileira contemporânea. 7.ed. São Paulo: Atlas, 2009.

JUSTEN FILHO, Marçal. Curso de direito administrativo. São Paulo: Saraiva, 2005.

MODIANO, Eduardo. A ópera dos três cruzados: 1985-1989. In: ABREU, Marcelo de Paiva (Org.). A ordem do progresso: cem anos de política econômica republicana 1889-1989. Rio de Janeiro: Campus, 1999. p. ini.-fin.

PÉREZ LUÑO, Antonio-Enrique. La seguridad jurídica. 2.ed. Barcelona: Ariel, 1994. 
PORTO, Antônio José Maristrello. Análise econômica da responsabilidade civil. In: TIMM, Luciano Benetti. Direito e economia no Brasil. São Paulo: Atlas, 2012.

RODRIGUEZ, José Rodrigo. Segurança jurídica e desenvolvimento. In: . Fragmentos para um dicionário crítico de direito e desenvolvimento. São Paulo: Saraiva, 2011.

Artigo recebido em 14/10/13 e aprovado para publicação em 20/11/13

Como citar: GODOY, Edvania Fátima Fontes; KEMPFER, Marlene. Planos econômicos de estabilização nacional: uma análise sob o enfoque da responsabilidade extracontratual do estado e da segurança jurídica. Scientia Iuris, Londrina, v.17, n.2, p.75-106, dez.2013. DOI: 10.5433/21788189.2013v17n2p75. 